\title{
Hepatitis B seroprevalence in hematological oncology patients
}

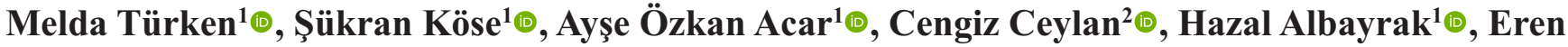 \\ Arkalı ${ }^{1}$
}

${ }^{1}$ Department of Infectious Diseases and Clinical Microbiology, University of Health Sciences, Tepecik Training and Research Hospital, Izmir, Turkey

${ }^{2}$ Department of Clinical Hematology, University of Health Sciences, Tepecik Training and Research Hospital, Izmir, Turkey

\section{ABSTRACT}

Objectives: Hepatitis B virus (HBV) infection is still a serious public health problem today. Many factors such as frequent blood transfusion, hemodialysis, sexual contact, sterilization in surgical procedures, etc. are involved in the transmission of hepatitis B virus. In our study, HBV seroprevalence was evaluated retrospectively in order to provide vaccination of anti-HBs negative patients and to determine HBV prophylaxis in patients with hematological malignancy.

Methods: A total of 499 patients were included in the study. HBsAg, anti-HBs, anti-HBc IgG, anti-HDV, HBV DNA values were measured by ELISA (enzyme-linked immunosorbent assay, Liason, Diasorin, Italy) with Real-Time PCR (Cobas-Tagman, Roche Switzerland) and recorded. The obtained datas were evaluated by SPSS for Windows 15.00 statistical program. A value of $p<0.05$ was accepted as a statistical significance value.

Results: HBsAg positivity was found to be $3.4 \%(n=17)$ in all patients. Appropriate treatment regimens were started to patients with HBsAg $(+)$. There were $166(33.3 \%)$ patients with anti-HBs $(+)$. One hundred nineteen $(23.8 \%)$ patients had anti-HBc IgG $(+), 40(33.6 \%)$ of them were started a prophylactic treatment regimen. Anti-HBs positivity were reported after vaccination in $48(16.8 \%)$ patients. Occult hepatitis have not been detected in patients with anti-HBc IgG positivity.

Conclusions: As a result of this study, anti-HBs negative patients with hematological malignancies were vaccinated. Patients and physicians should be informed about vaccination and hepatitis serology controls of hematological malignancy and other immunosuppressed patients. Sensitivity in this context should be increased in terms of prophylactic treatments.

Keywords: Hepatitis B virus, seroprevalence, hematological malignancy, oncology

$\mathrm{H}$ epatitis B virus (HBV) infection is still a serious public health problem today. The prevalence of HBV in Turkey, an area where HBV infection is moderately endemic, is reported to be $2-7 \%$, depending on the region [1]. In recent years there has been a decrease in carrier rates because of hepatitis B vaccina- tion becoming more and more common [2].

Many factors such as frequent blood transfusion, hemodialysis, sexual contact, sterilization in surgical procedures, etc. are involved in the transmission of HBV [3]. Immunosuppressive therapies (such as steroids, cytotoxic chemotherapies) and frequent 
blood transfusions causing hematologic oncology patients to be involved in the risk group [4]. Due to the presence of viral hepatitis-associated exacerbations during the given immunosuppressive treatments $\mathrm{HBsAg}$, anti-HBs, anti-HBc IgG screening especially important in this patient groups. HBV DNA testing should be performed in the case of HBsAg and / or anti-HBc IgG positivity [5]. Entecavir or tenofovir should be chosen for prophylactic treatment. Prophylactic treatment should be initiated as soon as possible in the HbsAg-positive patient (one week before or concurrent with immunosuppressive treatment, if possible) without losing time. Antiviral treatment should be continued for at least 12 months after immunosuppressive treatment, In case of HBsAg negative and anti-HBc positivity, prophylactic treatment is recommended if there is HBV DNA positivity. Patients in the low-risk group due to risky reactivation should be monitored at 3-month intervals with HBV DNA control [6]. Therefore, screening for viral hepatitis in all hematologic oncology patients is important.

In our study, it was aimed to determine the seroprevalence of HBV in patients who were diagnosed with hematologic malignancy in our hospital, to determine the patients who were anti-HBs negative but not yet vaccinated and to be vaccinated and to identify the patients who started treatment as prophylactic.

\section{METHODS}

We retrospectively reviewed our patients who were diagnosed with hematological cancer in the hematology clinic of İzmir Tepecik Training and Research Hospital between 2007-2016. Ethics committee approval was taken from the local ethics committee in İzmir Tepecik Training and Research Hospital. Patients were examined retrospectively from patient records and files for demographic characteristics, hematologic cancer diagnosis, which treatment was initiated if treatment or prophylaxis were given. Those who were younger than 18 years of age and were pregnant were not included in the study. A total of 499 patients were included in the study. Anti-HBc IgG, anti-HDV, HBV DNA values were measured by ELISA (enzyme-linked immunosorbent assay, Liason, Diasorin, Italy) with Real-Time PCR (Cobas-Tagman, Roche Switzerland) and recorded.

\section{Statistical Analysis}

The obtained datas were evaluated by SPSS for Windows 15.00 statistical program. A value of $p<$ 0.05 was accepted as a statistical significance value. The mean age of the case groups was shown as mean \pm SD. The Kolmogorov-Smirnov test was used to assess whether the datas were fit to normal distribution. Mann-Whitney $U$ test was used to compare the continuous variables of independent groups that did not show normal distribution. Group comparisons of nonparametric continuous variables belonging to more than 2 groups were made by Kruskal Wallis test.

\section{RESULTS}

A total of 499 patients with hematologic malignancy were included in the study. One hundred ninety-two $(38.4 \%)$ patients were female. The mean age of the patients was $61.02 \pm 16.25$ years (Table 1 ). The most common hematological malignancies were multiple myeloma (MM), chronic lymphoblastic leukemia (CLL), acute myeloid leukemia (AML), chronic myeloid leukemia (CML), non-Hodgkin's lymphoma (NHL), Hodgkin's lymphoma (HL), acute lymphoblastic leukemia (ALL), Myelofibrosis, Hairy Cell Leukemia (HCL) respectively (Table 2).

HBsAg positivity was found to be $3.4 \%(n=17)$ in all patients (Table 2). Appropriate treatment regimens were started to patients with $\mathrm{HBsAg}(+)$. There were $166(33.3 \%)$ patients with anti-HBs $(+)$. One hundred nineteen $(23.8 \%)$ patients had anti-HBc

Table 1. Distribution of patients by gender and age

\begin{tabular}{lcccc}
\hline Gender & $\mathbf{n}$ & Mean & Standard Deviation & Group median value \\
\hline Female & 192 & 63.04 & 15.15 & 64.38 \\
Male & 307 & 59.76 & 16.80 & 62.33 \\
Total & 499 & 61.02 & 16.25 & 63.26 \\
\hline
\end{tabular}


Table 2. Hepatitis B serological rate

\begin{tabular}{|c|c|c|c|c|c|c|c|}
\hline Diagnosis & $\begin{array}{l}\text { HBsAg } \\
\text { positive }\end{array}$ & $\begin{array}{c}\text { HBsAg } \\
\text { negative }\end{array}$ & $\begin{array}{c}\text { Anti- } \\
\text { HBsAg } \\
\text { positive }\end{array}$ & $\begin{array}{c}\text { Anti- } \\
\text { HBsAg } \\
\text { negative }\end{array}$ & $\begin{array}{c}\text { Anti-HBc } \\
\text { IgG } \\
\text { positive }\end{array}$ & $\begin{array}{c}\text { Anti-HBc } \\
\text { IgG } \\
\text { negative }\end{array}$ & Total \\
\hline MM, n (\%) & $5(4.3)$ & $112(95.7)$ & $40(32.4)$ & $77(65.8)$ & $33(28.2)$ & $84(71.8)$ & $117(100)$ \\
\hline CML, n (\%) & $0(0)$ & $73(100)$ & $21(28.8)$ & $52(71.2)$ & $17(23.3)$ & $56(76.7)$ & $73(100)$ \\
\hline CLL, n (\%) & $3(3.1))$ & 94 (96.9) & $28(28.9)$ & $69(71.1)$ & $24(24.7)$ & $73(75.3)$ & $97(100)$ \\
\hline AML, n (\%) & $4(4.7)$ & $82(95.3)$ & $43(50)$ & $43(50)$ & $28(32.6)$ & $58(67.4)$ & $86(100)$ \\
\hline ALL, n (\%) & $1(8.3)$ & $11(91.7)$ & $4(33.3)$ & $8(66.7)$ & $1(8.3)$ & $11(91.7)$ & $12(100)$ \\
\hline NHL, n (\%) & $1(1.5)$ & $65(98.5)$ & $18(27.3)$ & $48 / 72.4)$ & $8(12.1)$ & $58(90.9)$ & $66(100)$ \\
\hline HL, n (\%) & $2(5.9)$ & $32(94.1)$ & $6(17.6)$ & $28(82.4)$ & $3(8.9)$ & $31(91.1)$ & $34(100)$ \\
\hline Myelofibrosis, n (\%) & $1(12.5)$ & $7(87.5)$ & $3(37.5)$ & $5(62.5)$ & $4(50)$ & $4(50)$ & $8(100)$ \\
\hline HCL, n (\%) & $0(0)$ & $6(100)$ & $3(50)$ & $3(50)$ & $1(16.7)$ & $5(83.3)$ & $6(100)$ \\
\hline Total, n (\%) & $17(3.4)$ & $482(96.6)$ & $166(33.3)$ & $333(66.7)$ & $119(23.8)$ & $380(76.1)$ & $499(100)$ \\
\hline
\end{tabular}

IgG (+), $40 \quad(33.6 \%)$ of them were started a prophylactic treatment regimen. Anti-HBsAg positivity were reported after vaccination in 48 $(16.8 \%)$ patients. Occult hepatitis has not been detected in anti-HBc IgG positive patients.

\section{DISCUSSION}

Natural course of hepatitis B infection is determined by the interaction between virus replication and the immune response of the host. HBV continues its existence in the HBV infected patients even if the serologic markers become negative. Therefore, there is a risk of $\mathrm{HBV}$ reactivation with immunosuppressive treatment in individuals who are infected with HBV. HBV reactivation may lead to the delay of treatment of primary disease and even to the ceasing of chemotherapy in these patients [7].

Turkey is among the moderately endemic $(2-7 \%)$ regions due to hepatitis $\mathrm{B}$ infection [1]. While these rates vary according to the regions, the frequency of the HbsAg in the studies conducted in our country is found between $0.8-5.7 \%$. According to the data obtained from the Turkish Red Crescent Blood Center, HbsAg positivity was found to be $0.6 \%$ in 2012 [8]. When HBsAg positivity is evaluated in our country, Eastern and Southeastern Anatolia Region is found to be have higher rates than other regions [9]

In a study performed by Sardaş et al. [10], HBsAg of $16 \%$ and anti-HBs of $54 \%$ positivity were detected in hematology-oncology patients who received frequent transfusions. In control groups who never received transfusions $\mathrm{HBsAg}$ positivity of $4 \%$ and anti-HBs positivity of $22 \%$ were detected. It was concluded that patients who received frequent blood transfusions were under a higher risk of hepatitis B infection [10].

In a study by Sar1 et al. [11], two groups were separated as transfusion and non-transfusion patients with hematological malignancy, and a third control group with no additional disease was established. HBsAg seropositivity in the first group was found to be $22.8 \%$, in the second group $5.7 \%$ and in the third group $9 \%$. In this study HBsAg seropositivity was found to be higher in patients with hematological malignancy and received frequent blood transfusion $(p<0.05)$ [11]. Köse et al. [12] worked with 448 oncology patients in İzmir Tepecik Training and Research Hospital between 2006 and 2007. In their study, 19 (4.2\%) HBsAg positivity was detected in the patients.

In some studies, it has been suggested that hepatitis $\mathrm{B}$ and $\mathrm{C}$ viruses may be associated with various lymphoid neoplasms because these viruses that can multiply in the lymphoid tissue. In the study 
conducted by Yalçıntaş Arslan et al. [13], 165 noncancer patients with 164 NHL were taken and 15 (9.1\%) patients were found to be HbsAg positive and $3(1.8 \%)$ patients were Anti-HCV positive. According to the control group, $\mathrm{Hbs} \mathrm{Ag}$ positivity was high and anti-HCV positivity was found to be similar in patients with NHL [13]. In our study, HbsAg positivity was found to be $1.5 \%(1 / 67)$ in patients with NHL, but no significant difference was found compared to other groups $(p>0.05)$.

In some studies, the relationship between MM and HBV and HCV infection was investigated. In a study by Huang et al. [14] 299 patients with MM and 299 patients with acute leukemia (AL) were evaluated. HbsAg positivity was found to be $19.4 \%$ in the MMdiagnosed group and $12 \%$ in the AL-diagnosed group and there was a significant difference between the two groups in terms of HbsAg positivity ( $p=0014$ ) [14]. In our study, 5 (4.3\%) HbsAg positivity was detected in 117 patients with MM. However, when compared with the other groups, there was no significant difference in $\mathrm{HbsAg}$ positivity in patients with $\mathrm{MM}(p$ $>0.05)$

Occult HBV infection is characterized by HBsAg negativity with persistence of low HBV DNA levels, regardless of Anti-Hbc IgG positivity. Immunosuppressive therapies are also likely to cause reactivation in this patient group [15]. The risk of reactivation by immunosuppression is much less than that of the HbsAg positive patient group. In one study with $204 \mathrm{HbsAg}$ negative serum samples taken before cancer chemotherapy from cancer patients, isolatedanti-Hbc IgG positivity was detected in 11 (5.4\%) patients. HBV DNA positivity was detected in $9(81 \%)$ of these 11 patients. Patients with hematologic malignancy had a higher incidence of occult hepatitis B compared to the group with solid organ malignancy. There was no significant difference between anti-HBc IgG positivity and frequent blood transfusions, familial hepatitis and biochemical parameters (AST, ALT) $(p>0.05)[16]$.

Although there are many seroprevalence studies with patients in the risk group such as transfusion, dialysis etc. there is a limited number of seroprevalence studies performed with hematological oncology patients [4]. The prophylactic treatment regimens initiated for the disease are lamivudine, tenofovir, entecavir. In our study, it was found that many patients who were diagnosed as anti-HBsAg negative $333(66.7 \%)$ were not vaccinated.

\section{CONCLUSION}

As a result of this study, vaccination of AntiHBsAg negative patients were provided with hematology clinic. In conclusion, patients and physicians should be informed about vaccination and hepatitis serology controls of hematological malignancy and other immunosuppressed patients. Sensitivity in this context should be increased in terms of prophylactic treatments.

\section{Ethical Statement}

All procedures performed in studies involving human participant were in accordance with the ethical standards of the institutional and/ or national research committee and with the 1964 Helsinki declaration and its later amendments of comparable ethical standards.

\section{Conflict of interest}

The authors disclosed no conflict of interest during the preparation or publication of this manuscript.

\section{Financing}

The authors disclosed that they did not receive any grant during conduction or writing of this study.

\section{REFERENCES}

1. Deveci Ö, Tekin A, Günbay SS, Kılıç D, Kaygusuz S, Ağalar $\mathrm{C}$, et al. [Evaluation of HBsAg, anti-HCV, anti-HIV and VDRL test results in blood donors]. J Clin Exp Invest 2011;2:416-9. [Article in Turkish]

2. Lavanchy D. Worldwide epidemiology of HBV infection, disease burden, and vaccine prevention. J Clin Virol 2005;34 Suppl 1:S1-3.

3. Greeley RD, Semple S, Thompson ND, High P, Rudowski E, Handschur E, et al. Hepatitis B outbreak associated with a hematology-oncology office practice in New Jersey, 2009. Am J Infect Control 2001;39:663-70.

4. Utkan G, Azap A, Muallaoğlu S, Tokluoğlu S, Durnalı AG, Arslan ÜY, et al. [Hepatitis B and C seroprevalence in cancer patients: a case control study]. Int J Hematol Oncol 2006;16:1037. [Article in Turkish]

5. European Association for the Study of the Liver. EASL 2017 Clinical Practice Guidelines on the management of hepatitis B virus infection. J Hepatol 2017;67:370-98. 
6. Turkey Viral Hepatitis Diagnosis and Treatment Guide 2017. Available at: http://www.vhsd.org/tr/page/turkiye-viralhepatitliler-tani-ve-tedavi-kilavuzu-2-7.html May 2017. [Article in Turkish]

7. Uptodate 2017 Hepatitis B virus reactivation associated with immunosuppressive therapy. Available at: www.uptodate.com/contents/hepatitis-b-virus-reactivationassociated-with-immunosuppressive-therapy Dec 18, 2017. 8. Tosun S. [The changing viral hepatitis epidemiology in our country]. Ankem Derg 2013;27(suppl 2):128-34.

9. İnci A, Okay M, Güven D. [HBsAg, Anti-HBs, Anti-HCV and Anti-HIV seroprevalence of the patients applied to Artvin State Hospital]. Viral Hepatit Derg 2013;19:41-4. [Article in Turkish] 10. Şardaş OS, Tekeli E, Koç H, Balık İ, Dağcı Ş, Ertural F. [The prevalence of the hepatitis B virus markers in the haematologicongologic patients who had frequently received transfusion]. Turkiye Klinikleri J Med Res 1990;8:171-4. [Article in Turkish] 11. Sarı R, Özkan Hİ, Sevinç A, Aydoğdu İ. [Seropositivity of hepatitis $\mathrm{B}$ and hepatitis $\mathrm{C}$ viruses in blood and blood products in transfused and non-transfused patients with hematological malignancies]. Turgut Özal Tıp Merkezi Dergisi 2000;7:109-12. [Article in Turkish]

12. Kose S, Olmezoglu A, Gozaydin A, Ece G. Seroprevalence of hepatitis B and C among oncology patients in Turkey. J Health Popul Nutr 2011;29:652-5.

13. Yalçıntaş Arslan Ü, Önder FO, Uncu D, Tokluoğlu S, Gök Durnalı A, Çelenkoğlu G, et al. [Hepatitis B and C Virüs Seroprevalance of the Patients vvith Non-Hodgkin's Lymphoma: Single Center Experience]. Acta Oncologica Turcica 2009;42:279. [Article in Turkish]

14. Huang B, Li J, Zhou Z, Zheng D, Liu J, Chen M. High prevalence of hepatitis B virus infection in multiple myeloma. Leuk Lymphoma 2012;53: 270-4.

15. Samal J, Kandpal M, Vivekanandan P. Molecular mechanisms underlying occult hepatitis B virus infection. Clin Microbiol Rev 2012;25:142-63.

16. Baghbanian M, Halvani M, Roghani HS, Lofti MH, Yazdi MF, Vahedian-Ardakani HA. Prevalence of occult hepatıtıs B infection in Iranian cancer patients before chemotherapy treatment. Arq Gastroenterol 2016;53:175-9. 